\title{
Prevalence of ESR1 E380Q mutation in tumor tissue and plasma from Japanese breast cancer patients
}

\author{
Takashi Takeshita', Yutaka Yamamoto', Mutsuko Yamamoto-lbusuki ${ }^{2}$, Aiko Sueta', Mai Tomiguchi', \\ Keiichi Murakami ${ }^{1}$, Yoko Omoto ${ }^{1,3}$ and Hirotaka Iwase ${ }^{1 *}$
}

\begin{abstract}
Background: ESR1 mutations have attracted attention as a potentially important marker and treatment target in endocrine therapy-resistant breast cancer patients. The E380Q mutation, which is one of the ESR1 mutations, is associated with estradiol (E2) hypersensitivity, increased DNA binding to the estrogen response element, and E2-independent constitutive trans-activation activity, but its frequency in ESR1 mutations remains unknown. The present study aimed to investigate the $\mathrm{E} 380 \mathrm{Q}$ mutation in comparison with the other representative ESR1 mutations.

Methods: We screened a total of 62 patients (66 tumor tissues and 69 plasma cell-free DNA (cfDNA)) to detect ESR1 mutations (E380Q, Y537S, Y537N, Y537C, and D538G) using droplet-digital polymerase chain reaction. Plasma was collected at more than two points of the clinical course, in whom changes of ESR1 mutations under treatment were investigated.
\end{abstract}

Results: We detected ESR1 mutations in 21\% (12/57) of MBCs. The E380Q ESR1 mutation was found in 16\% (2/12) and the other ESR1 LBD mutations were five (41.6\%) of Y537S, and four each (33.3\%) of D538G, Y537N, and Y537C, in 12 ESR1 mutant breast cancer patients. Five tumors had multiple ESR1 mutations: three had double ESR1 mutations; Y537S/E380Q, Y37S/Y537C, and Y537S/D538G, and two had triple ESR1 mutations; Y537S/Y537N/D538G. In plasma cfDNA analysis, the E380Q mutation was not detected, but increases in other ESR1 mutations were detected in 46.2\% (6/13) of MBC patients under treatment.

Conclusions: We have shown that there are distinct populations of ESR1 mutations in metastatic tissue and plasma. Each ESR1 mutation may have different clinical significance, and it will be necessary to investigate them all.

Keywords: Metastatic breast cancer, Acquired endocrine therapy resistance, ESR1 mutations, E380Q mutation, Cell-free DNA

\section{Background}

ESR1 ligand-binding domain (LBD) mutations that induce endocrine therapy (ET) resistance in breast cancer (BC) were first reported almost two decades ago [1-4] and novel developments of sensitive technologies such as nextgeneration sequencing (NGS) confirmed that ESR1 LBD mutations act as drivers of ET resistance [5-8]. In addition, recent developments of digital genomic technologies

\footnotetext{
* Correspondence: hiwase@kumamoto-u.ac.jp

${ }^{1}$ Department of Breast and Endocrine Surgery, Graduate School of Medical Sciences, Kumamoto University, 1-1-1 Honjo, Chuo-ku, Kumamoto City 860-8556, Japan

Full list of author information is available at the end of the article
}

revealed that plasma cell-free DNA (cfDNA) is an useful source to quickly assess the mutational profiles and monitor the molecular changes under treatment [9]. It has been reported the clinical significance of monitoring ESR1 LBD mutations in plasma cfDNA [10-12]. In the BOLERO-2 study, Chandarlapaty and colleagues found that a total of $155(28.8 \%)$ of 541 ER-positive MBC patients had the D538G and/ or the Y537S ESR1 mutation in plasma cfDNA, which are the representative ESR1 LBD mutations, and each of them was associated with shorter overall survival [13]. Interestingly, they also demonstrated an additional benefit of the use of mTOR (mammalian target of rapamycin) inhibitor depending on the ESR1 LBD 
mutation present; the D538G ESR1 mutation derived a large benefit from treatment with an mTOR inhibitor, whereas those with the Y537S mutation did not. These data suggest that each ESR1 LBD mutation may play a different role and more work is needed to confirm this.

Pakdel and colleagues [14] found that mutation of the one charged amino acid, E380Q, resulted in a requirement for less estradiol than wild-type (WT) ESR1 to achieve maximal activity and this mutation also showed high trans-activation activity in the absence of added hormone. They suggested that this ESR1 LBD mutation may be important in DNA binding and protein-protein interactions that modulate transcriptional activity of the estrogen receptor (ER). After 20 years, the presence of the E380Q ESR1 mutation came to be reported in both tumor tissue DNA (ttDNA) and plasma cfDNA [10, 14-19]. In the recent phase 2 clinical trial for plasma cfDNA of aromatase inhibitor (AI) resistant metastatic $\mathrm{BC}(\mathrm{MBC})$ patients, this mutation was found in 26\% (15/57) of ESR1 mutant plasma samples [18]. Fribbens and colleagues reported that the E380Q ESR1 mutation was found in 9.5\% (6/63) in the SoFEA study for hormone receptor (HR)-positive $\mathrm{BC}$ patients who had demonstrated prior sensitivity to AIs, but it was found in 24.4\% (22/91) in the PALOMA3 trial for HR-positive $\mathrm{BC}$ patients who had progressed during prior ET [19]. These results suggest that E380Q ESR1 mutation may be a marker for screen of ET-resistant BC like the other representative ESR1 LBD mutations (Y537S, Y537N, Y537C, and D538G) [10-12, 20]. However, the literature contains little information regarding the E380Q ESR1 mutation in Japanese BC patients. Thus, the present study screened for the presence of the ESR1 E380Q mutation in ttDNA and plasma cfDNA of 62 ER-positive Japanese $\mathrm{BC}$ patients using droplet digital polymerase chain reaction (ddPCR) and compared the frequency with the representative ESR1 LBD mutations (Y537S, Y537N, Y537C, and D538G). To our knowledge, this is the only precise study to use ddPCR to examine the presence of the E380Q ESR1 mutations in a series of tumor tissue and plasma samples of Japanese BC patients.

\section{Methods}

\section{Patients and breast cancer samples}

A total of 62 patients (9 tumor tissue and 18 plasma samples in the primary $\mathrm{BC}(\mathrm{PBC})$ group and 57 tumor tissue and 51 plasma samples in the MBC group), treated at Kumamoto University Hospital between 2005 and 2014, were enrolled in this study. Informed consent was obtained from all patients before biopsy or surgery. The Ethics Committee of Kumamoto University Graduate School of Medicine (Kumamoto, Japan) approved the study protocol. The treatment for PBC was carried out in accordance with the recommendations of the St. Gallen international expert consensus on the primary therapy of early $\mathrm{BC}$ at that time and the treatment for MBC was carried out in accordance with the National Comprehensive Cancer Network Clinical Practice Guidelines in Oncology [21]. Patients were examined at the Kumamoto University Hospital or affiliated hospitals and were assessed for the presence or absence of relapse and for clinical response, which was defined according to the Response Evaluation Criteria in Solid Tumors as complete response, partial response, stable disease, or progressive disease during the follow-up period as described previously [22].

\section{Sample preparation}

Tumor cells and plasma were processed and each solution, which was examined for quality and quantity, was used as template ttDNA and cfDNA for the analysis of ESR1 mutations, respectively, as described elsewhere [22].

\section{Analysis of ESR1 mutations by ddPCR}

ddPCR assay was performed on the same sample twice using the QX200 Droplet Digital ${ }^{\text {mo }}$ PCR System (Bio-Rad Laboratories, Hercules, CA, USA) and PCR data were quantified using QuantaSoft" software (Bio-Rad Laboratories) and results are expressed as fractional abundance (mutant allele frequency: MAF) for each tumor tissue sample and as copies/ $\mu \mathrm{L}$ of mutant DNA for each plasma sample as described previously [22]. Our ddPCR analysis of four representative ESR1 LBD mutations (Y537S, Y537N, Y537C, and D538G) had already been optimized by comparative analysis of a dilution series of each synthetic ESR1 LBD mutant oligonucleotide as reported previously [20]. All samples were compared with the ESR1 WT molecule and each ESR1 mutant molecule as positive control. A water-only (no template) control and WT normal human DNA (TaqMan Control Genomic DNA) were run in parallel for each ddPCR reaction as negative control.

\section{Probes and primers}

We used LBx Probe ESR1 E380Q (\#65116) as the detection probe for ESR1 E380Q (Riken Genesis, Tokyo, Japan) and Custom TaqMan SNP Genotyping assays (Applied Biosystems, Foster City, CA, USA) for the detection of other ESR1 LBD mutations (Y537S, Y537N, Y537C, and D538G), as described previously [20].

\section{Site-directed mutagenesis}

The gene art site-directed mutagenesis system (Life Technologies) was used to generate mutations within ESR1 LBD. We generated ESR1 E380Q using PrimeSTAR ${ }^{\circ}$ GXL DNA polymerase (Takara Bio Inc., Shiga, Japan). WT ER expression vector (pcDNA-ER) was used as a template with the following mutagenesis primers:

E380Q: Forward, 5'-CTTCTACAATGTGCCTGGCT AGAGATCCT-3" 
Reverse, 5' -TACTAGTCCAGGTGGAAGATGTTACA CGGA -3',

The ESR1 mutant molecule for ddPCR was amplified using PCR based on the ESR1 mutated plasmid, as described [20].

\section{Immunohistochemistry}

Immunohistochemical staining for ER alpha, progesterone receptor (PgR), human epidermal growth factor receptor 2 (HER2), and Ki67 was carried out on selected 4- $\mu$ m thick tumor section. Primary antibodies, their visualization methods, and their evaluation were as previously described [23].

\section{Results}

\section{Patient characteristics}

A total of nine $(14.5 \%)$ of 62 women with $\mathrm{PBC}$ and a total of $53(85.5 \%)$ of 62 women with MBC were enrolled (Fig. 1). In the MBC patient group, four women were biopsied in heterochrony twice and $57 \mathrm{BC}$ specimens were evaluated for ESR1 mutation analysis. Baseline characteristics of primary and metastatic ER-positive $\mathrm{BC}$ specimens are summarized in Table 1 . The median age of the patients at tumor tissue biopsy was 56 years (range, 31-68) in the PBC group and 58 years (range, 31-95) in the MBC group. In the primary clinical stage, eight patients (14\%) were categorized as stage III and ten $(17.5 \%)$ as stage IV in the MBC group. Four representative ESR1 LBD mutations (Y537S, Y537N, Y537C, and D538G) were previously evaluated with all samples of this study $[12,20]$. The median number of metastatic organs was two (range, $1-5$ ) and $49.1 \%$ of the patients had visceral metastasis. The median number of prior ET and prior chemotherapy treatments was two (range, 0-6) and 0 (range, 0-6), respectively. The median duration of follow-up was 77 months (range, 25-113) in the PBC group and 97 months (range, 4-290 months) in the $\mathrm{MBC}$ group.

\section{Quantitative analysis of ddPCR using the ESR1 E380Q mutant molecule}

Comparative ddPCR analysis of a dilution series of the indicated synthetic ESR1 E380Q oligonucleotide is presented in Fig. 2a. We used serial dilutions of the ESR1 E380Q molecule and analyzed them by ddPCR. A mixture of recombinant ESR1 E380Q and WT ESR1 was plotted against the different fractional concentrations from 32 to 0 copies/ $\mu \mathrm{L}$. The MAF of ESR1 E380Q was maintained at more than two droplets. Therefore, a mutation was only considered to be present if more than two positive droplets were detected. In addition, we performed dilution experiments where the ESR1 E380Q oligonucleotide was diluted in a background of WT normal human DNA (Fig. 2b-d). The dilution experiments were prepared by 1.3-fold serial dilution of synthetic ESR1 E380Q stock oligonucleotide in a background of WT normal human DNA (TaqMan Control Genomic DNA) where the total DNA content of the ddPCR reaction was $20 \mathrm{ng}$ and "WT double" was $40 \mathrm{ng}$. We confirmed that this assay was able to detect the ESR1 E380Q molecule in a background of WT normal human DNA with the lowest concentration and was not able to detect any false-positives in the WT normal human DNA.

\section{The frequencies of ESR 1 mutations in primary and metastatic breast cancer patients}

We screened nine PBC and $57 \mathrm{MBC}$ tumors to detect ESR1 E380Q and the other ESR1 LBD mutations (Y537S, Y537N, Y537C, and D538G). The rates of ESR1 mutations in primary and metastatic tumors from BC

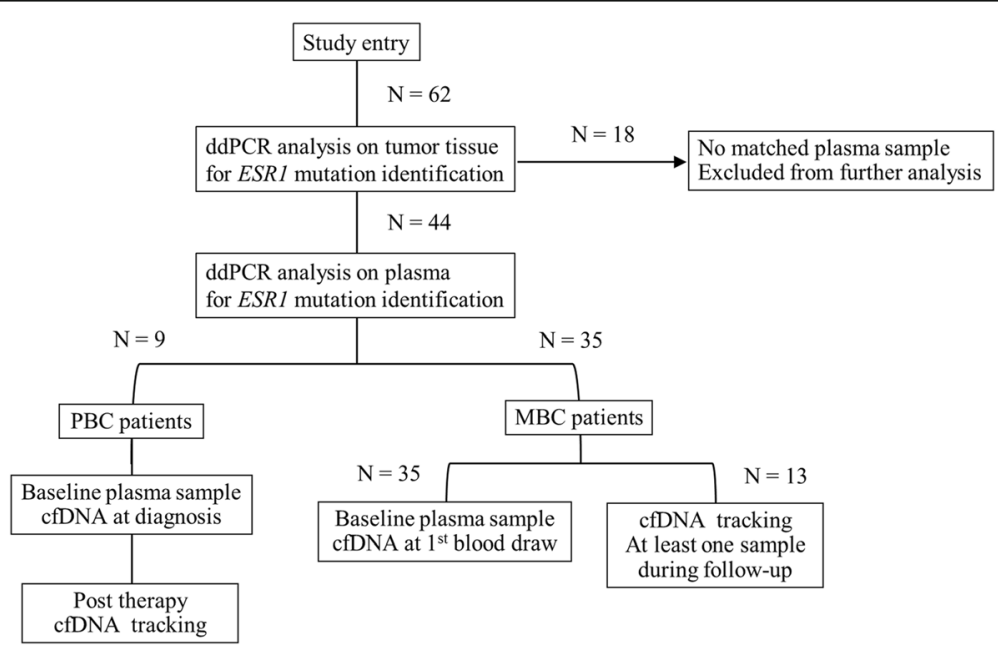

Fig. 1 Schematic presentation of the protocol used in the present study. Abbreviations; ddPCR, droplet digital polymerase chain reaction; PBC, primary breast cancer; $M B C$, recurrent metastatic breast cancer; cfDNA, cell-free DNA 
Table 1 Patient characteristics

\begin{tabular}{|c|c|c|}
\hline & No. of patient & \\
\hline & $\overline{P B C}$ & $\mathrm{MBC}$ \\
\hline Variables & $(N=9)$ & $(N=57)$ \\
\hline Age at biopsy & & \\
\hline Median (range) & $56(31-68)$ & $58(31-95)$ \\
\hline Primary clinical stage & & \\
\hline 1 & $2(22.2)$ & $22(38.6)$ \\
\hline$\|$ & $6(66.7)$ & $17(29.8)$ \\
\hline III & $1(11.1)$ & $8(14)$ \\
\hline IV & 0 & $10(17.5)$ \\
\hline Histological type & & \\
\hline Invasive ductal & $9(100)$ & $53(93)$ \\
\hline Invasive lobular & 0 & $3(5.3)$ \\
\hline Mucinous & 0 & $1(1.8)$ \\
\hline Histological grade & & \\
\hline 1 & $6(66.7)$ & $10(17.5)$ \\
\hline 2 & $2(22.2)$ & $27(47.4)$ \\
\hline 3 & $1(11.1)$ & $17(29.8)$ \\
\hline Lobular & 0 & $3(5.2)$ \\
\hline $\begin{array}{l}\text { Median percentage of ERa } \\
(25 \%, 75 \%)\end{array}$ & $90(75,92.5)$ & $85(70,90)$ \\
\hline $\begin{array}{l}\text { Median percentage of } \mathrm{PgR} \\
(25 \%, 75 \%)\end{array}$ & $10(5,45)$ & $30(5,60)$ \\
\hline HER2 & & \\
\hline Positive & 0 & $5(8.7)$ \\
\hline Negative & $9(100)$ & $52(91.2)$ \\
\hline Presence of ESR1 LBD mutat & & \\
\hline Yes & 0 & $11(19.3)$ \\
\hline No & $9(100)$ & $46(80.7)$ \\
\hline Number of metastatic organ & & \\
\hline Median (range) & & $2(1-5)$ \\
\hline Visceral involvement & & \\
\hline Yes & & $28(49.1)$ \\
\hline No & & $29(50.9)$ \\
\hline Metastatic lesions biopsied & & \\
\hline Breast & & $9(15.8)$ \\
\hline Skin & & $19(33.3)$ \\
\hline Lymph Nodes & & $14(24.6)$ \\
\hline Bone & & $4(7.0)$ \\
\hline Lung & & $3(5.2)$ \\
\hline Liver & & $4(7.0)$ \\
\hline Brain & & $3(5.2)$ \\
\hline Ovary & & $1(1.8)$ \\
\hline $\begin{array}{l}\text { Number of rounds of prior } \\
\text { endocrine therapy }\end{array}$ & & \\
\hline Median (range) & & $2(0-6)$ \\
\hline $\begin{array}{l}\text { Number of rounds of prior } \\
\text { chemotherapy }\end{array}$ & & \\
\hline Median (range) & & $0(0-6)$ \\
\hline
\end{tabular}

Abbreviations: $E R a$ estrogen receptor alpha, $P g R$ progesterone receptor, HER2 human epidermal growth factor receptor 2, $L B D$ ligand binding domain, $A l$ aromatase inhibitor, SERM selective estrogen receptor modulator, IBTR ipsilateral breast cancer recurrence patients are shown in Table 2. We detected ESR1 mutations in $21 \%(12 / 57)$ of MBCs, but could not detect them in primary breast tumors. The E380Q ESR1 mutation was found in $16 \%(2 / 12)$ of ESR1 mutant MBC patients, with a MAF of $21.7 \%$ (Case M43) and $2.69 \%$ (Case M50), respectively. Interestingly, two patients with the E380Q ESR1 mutation had multiple metastatic sites. Other ESR1 LBD mutations were five (41.6\%) of Y537S, and four each $(33.3 \%)$ of D538G, Y537N, and Y537C, in 12 ESR1 mutant BC patients. We observed five cases with multiple ESR1 LBD mutations in the same tumor: three had double ESR1 mutations; Y537S/E380Q, Y37S/ Y537C, and Y537S/D538G, and two had triple ESR1 mutations; Y537S/Y537N/D538G.

\section{Clinical course in patients with confirmed ESR1 E380Q}

Table 3 summarizes clinical characteristics and endocrine treatment history of patients with the E380Q ESR1 mutation identified in ttDNA. Case M43 had metachronous bilateral BC. Clinical recurrence was detected at 16 months during adjuvant ET. She had previously received systemic treatment with five different therapies, not including ET, before $\mathrm{MBC}$ resection. A resected breast tumor had the E380Q ESR1 mutation beyond the selected cut-off level. Hormonal therapy was administered in the adjuvant setting only and was not effective in this case. In case M50, ipsilateral breast tumor recurrence was detected at 72 months after primary surgery. This patient had received eight systemic therapies including four ETs before cervical lymph node biopsy. A cervical lymph node metastasis showed double ESR1 mutations, the Y537S and the E380Q ESR1 mutation, with a MAF of 12.8 and $2.69 \%$, respectively. Concerning the effect of ET, some ETs were initially effective, but, eventually, all ETs including AI became ineffective in this case. There were an insufficient number of samples to formally analyze a predicted association between the E380Q ESR1 mutation and patient prognosis.

\section{Plasma cfDNA analysis}

We screened the plasma cfDNA of nine PBC and $35 \mathrm{MBC}$ patients to detect the E380Q ESR1 mutation and the other ESR1 LBD mutations (Y537S, Y537N, Y537C, and D538G). Plasma was collected at more than two points of the clinical course in nine $\mathrm{PBC}$ and $13 \mathrm{MBC}$ patients (two blood draws in 10 patients and three blood draws in three patients) and we were able to investigate the change of ESR1 LBD mutations in plasma cfDNA under treatment (Fig. 1). A total of six (46.2\%) of $13 \mathrm{MBC}$ patients showed increases in cfDNA ESR1 LBD mutations under treatment and those were a useful tool, providing relevant predictive information as described previously [12]. However, the E380Q ESR1 mutation was not identified in either the 1st 
a

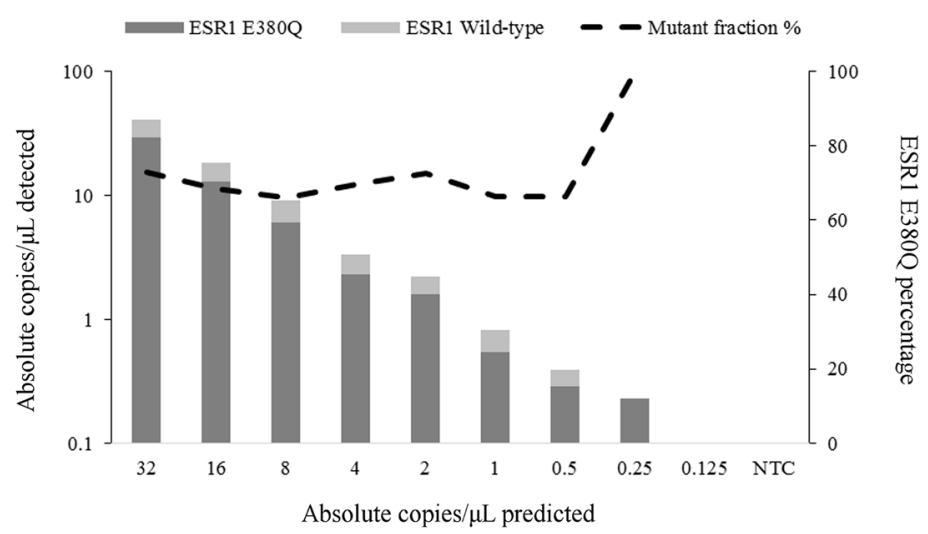

The number of positive droplets

$\begin{array}{lcccccccccc}\text { ESR1 E380Q } & 285 & 121 & 69 & 26 & 15 & 6 & 3 & 2 & 0 & 0 \\ \text { ESR1 Wild-type } & 107 & 53 & 36 & 11 & 6 & 3 & 1 & 0 & 0 & 0\end{array}$

b
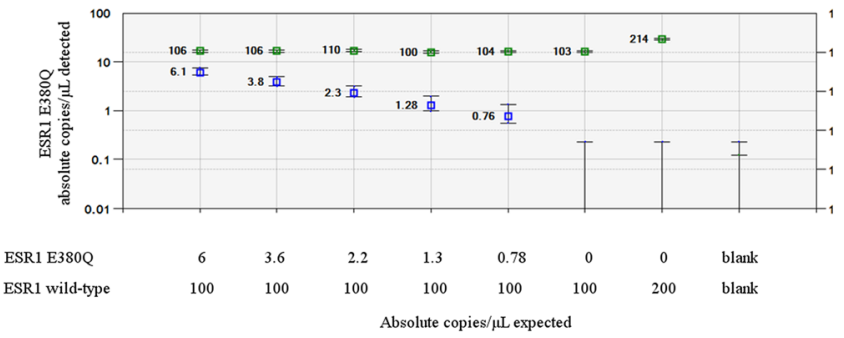

C

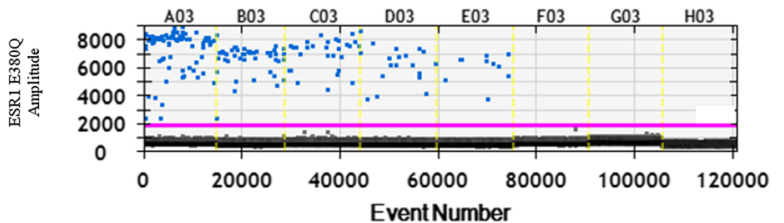

d

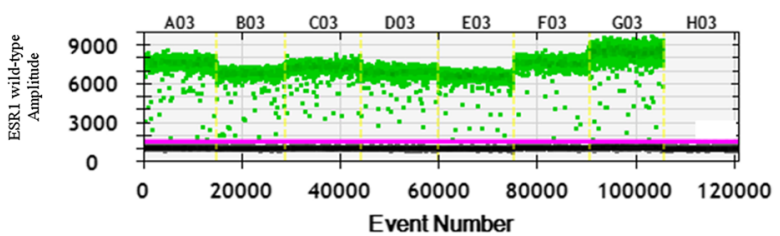

Fig. 2 a Comparative ddPCR analysis of a dilution series of the indicated synthetic ESR1 $\mathrm{E} 380 \mathrm{Q}$ oligonucleotide. We used serial dilutions of the ESR1 E380Q molecule and analyzed them by ddPCR. A mixture of recombinant ESR1 E380Q and WT was plotted against the different fractional concentrations from 32 to 0 copies/ $\mu \mathrm{L}$. The MAF of ESR1 E380Q was maintained at more than two droplets. Therefore, a mutation was only considered to be present if more than two positive droplets were detected. Abbreviations; ddPCR, droplet digital polymerase chain reaction; WT, wild-type; MAF, mutant allele frequency. b-d Dilution experiments where ESR1 E380Q oligonucleotide was diluted in a background of WT normal human DNA are shown. The dilution experiments were prepared by 1.3-fold serial dilution of synthetic ESR1 E380Q stock oligonucleotide in a background of WT normal human DNA (TaqMan Control Genomic DNA) where the total DNA content of each ddPCR reaction was 20 ng and "wild-type double" was 40 ng. b The box plots of ESR1 E380Q and ESR1 WT detected in each input DNA. c, d The fluorescent signal (C: ESR1 E380Q, d: ESR1 WT) for each droplet is plotted on the $y$-axis for each dilution, which is separated by a dotted yellow line, with input DNA indicated $\mathbf{b}$. The positive droplet fluorescence threshold is indicated by the magenta line. Blue dots represent FAM-labeled ESR1 E380Q mutant DNA (C), green dots represent HEX-labeled WT DNA (d), and black dots are droplets with no DNA incorporated. Each droplet is cumulatively counted as an 'Event Number' for the ddPCR experiments analyzed in tandem, and plotted along the $x$-axis. Abbreviations; WT, wild-type; ddPCR, droplet digital polymerase chain reaction

blood samples or the serial blood samples under treatment in either the PBC group or the MBC group. Additionally, the E380Q ESR1 mutation was not detected in plasma cfDNA even in two cases in which the E380Q ESR1 mutation was identified in ttDNA: in Case M43 no plasma was collected and the status of ESR1 mutation in 
Table 2 The number of ESR1 mutations in primary and metastatic tumors from breast cancer patients

\begin{tabular}{|c|c|c|c|c|c|c|c|c|}
\hline \multirow[t]{2}{*}{ Samples } & \multirow[t]{2}{*}{$N$} & \multicolumn{5}{|c|}{ ESR1 mutations } & \multirow{2}{*}{$\begin{array}{l}\text { Patients } \\
\text { with } \\
\text { ESR1 } \\
\text { mutation }\end{array}$} & \multirow{2}{*}{$\begin{array}{l}\text { Rate of ESRT } \\
\text { mutation }\end{array}$} \\
\hline & & E380Q & Y537S & Y537N & Y537C & D538G & & \\
\hline Primary & 9 & 0 & 0 & 0 & 0 & 0 & 0 & 0 \\
\hline \multicolumn{9}{|l|}{ Metastasis } \\
\hline Single site & 24 & 0 & 2 & 2 & 2 & 3 & $6^{a}$ & $25 \%(6 / 24)$ \\
\hline Multiple sites & 33 & 2 & 3 & 2 & 2 & 1 & $6^{b}$ & $18.2 \%(6 / 33)$ \\
\hline
\end{tabular}

${ }^{a}$ Two patients had polyclonal ESR1 mutations, Y537S/Y537N/D538G and Y537N/D538G

${ }^{\mathrm{b}}$ Three patients had polyclonal ESR1 mutations, Y537S/Y537N/D538G, Y537S/Y537C, and Y537S/E380Q

plasma cfDNA was therefore unidentified. In Case M50 plasma was collected and cfDNA was analyzed, but did not have the E380Q ESR1 mutation probably because the E380Q ESR1 mutation in ttDNA was in a subpopulation of cancer cells.

\section{Discussion}

In this study, we investigated the frequencies of the E380Q ESR1 mutation in comparison with the other ESR1 LBD mutations, Y537S, Y537N, Y537C, and D538G in tumor tissue and plasma DNA. In Vitro, Toy and colleagues showed differences in the ligandindependent activity among ESR1 LBD mutations [6]. More recently, they also found tumors driven by D538G, E380Q or S463P were effectively inhibited by fulvestrant, but, Y537S mutants were not fully inhibited by fulvestrant despite dosing to higher levels than are achieved in the hospital [24]. Therefore, identification of the frequency and characteristics of each ESR1 LBD mutation will deepen our knowledge and understanding of acquired ET resistance.

The raw data of E380Q ESR1 mutation is shown in Additional file 1: Table S1. The measurement results of two experiments were processed to one value with QuantaSoft ${ }^{\text {m }}$ software (Bio-Rad Laboratories). Four early representative studies on ESR1 mutations in ttDNA reported a total of one (2.5\%) of E380Q in comparison with a total of $14(35.8 \%)$ of D538G, $10(25.6 \%)$ of Y537S, four (10.2\%) of Y537N, three (7.6\%) of Y537C, and seven other ESR1 mutations among a total of 39 ESR1 LBD mutation-positive ER-positive MBC patients [5-8]. More recently, deep sequencing of 929 breast tumor biopsies (including ER-positive, HER2-positive and ER-negative tumors) indicated 95 patients (10.2\%) having somatic mutations in ESR1, which consisted of 20 (21.1\%) of E380Q, 34 (35.8\%) of D538G in comparison with $13(13.7 \%)$ of Y537S, 6 (6.3\%) of Y537C, and 5 (5.3\%) of Y537N [24]. Meanwhile, in the recent clinical trials for plasma cfDNA of ET resistance MBC patients, E380Q ESR1 mutation was found in 26\% (15/57) [18] and $24.2 \%(22 / 91)$ of ESR1 mutant plasma samples whose frequency was more than that of one of the major ESR1 LBD mutations, Y537N [19].

The frequency of the E380Q ESR1 mutation in our study seems to be rare among ESR1 LBD mutations. We found a total of two (16.6\%) E380Q ESR1 mutation out of $12 \mathrm{MBC}$ with ESR1 LBD mutations and we did not find the E380Q ESR1 mutation in plasma cfDNA (Table 2). Plasma cfDNA has the possibility to integrate ESR1 mutations from distinct populations of cells which are caused by inter- and/or intra-tumoral heterogeneity $[11,25]$. However, the E380Q ESR1 mutation was not identified in any of our 69 analyzed plasma cfDNA samples. In another small cohort of HR-positive Japanese MBC patients, whole exon sequencing of the ESR1 gene using NGS did not identify E380Q ESR1 mutation in their recurrent tumor samples and plasma samples [26].

Identifying associations between the status of the E380Q ESR1 mutation and response to ET will help to use ET more effectively. $\mathrm{Li}$ and colleagues detected the E380Q ESR1 mutation in an ER-positive patient-derived xenograft that reacted to tamoxifen, but was resistant to AI. [15]. De Mattos-Arruda and colleagues reported that the MAF of the E380Q ESR1 mutation in plasma cfDNA increased from 46 to $58 \%$ under disease progression [16]. However, in this study, there were an insufficient number of samples to formally analyze a predicted association between the E380Q ESR1 mutation and the patient's prognosis. The present study has limitations. This was a retrospective and single-institute study. Since this was a selected mutation-based study, not all the ESR1 LBD mutations were investigated. The number of patients with the E380Q ESR1 mutation was small due to the selection criteria. Although the appearance of ESR1 LBD mutations is closely associated with medical history of ET, this studied population is heterogeneously treated and we could not investigate whether or not the presence of ESR1 LBD mutations is dependent on specific hormone therapies.

\section{Conclusions}

We demonstrated the presence of a distinct population of ESR1 LBD mutations (E380Q, Y537S, Y537N, Y537C, 


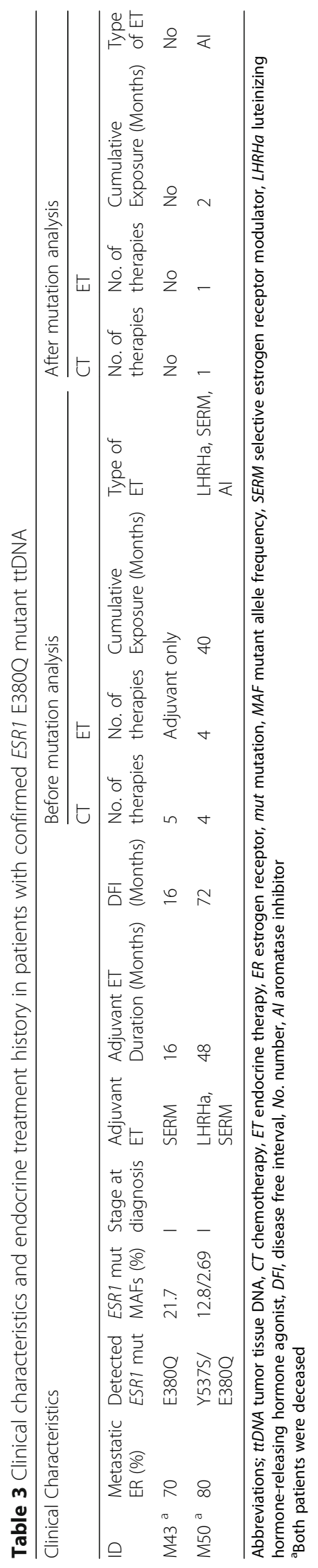


and D538G) in metastatic tissue and plasma using ddPCR assay. The identification of recurrent ESR1 mutations in metastatic ER-positive BCs may provide the basis of understanding ET resistance mechanisms, which may contribute to the development of new molecular targeted therapy.

\section{Additional file}

Additional file 1: Table S1. The raw data of E380Q ESR1mutation. Abbreviation: Conc., Concentration. (XLSX 15 kb)

\section{Abbreviations}

Al: Aromatase inhibitor; BC: Breast cancer; cfDNA: Cell-free DNA ddPCR: Droplet digital polymerase chain reaction; ER: Estrogen receptor; ET: Endocrine therapy; HER2: Human epidermal growth factor receptor 2; HR: Hormone receptor; LBD: Ligand-binding domain; LMD: Laser microdissection; MAF: Mutant allele frequency; MBC: Metastatic breast cancer; mTOR: Mammalian target of rapamycin; NGS: Next-generation sequencing; PBC: Primary breast cancer; PgR: Progesterone receptor; ttDNA: Tumor tissue DNA; WT: Wild-type

\section{Acknowledgements}

None.

\section{Funding}

No funding was obtained for this study. This work was supported in part by a grant-in-aid (project numbers 26461952 and 15K10057) for scientific research from the Ministry of Education, Science and Culture of Japan.

\section{Availability of data and materials}

The dataset supporting the conclusions of this article is included within the Article.

\section{Authors' contributions}

The study was conceived by $\Pi$ and $\mathrm{HI}$, $\Pi$ generated and assembled the data. TT, YY, MY-I, AS, MT, KM, YO, and HI developed and performed the data analysis and wrote the manuscript. All authors have read and approved of the final version of this manuscript.

\section{Ethics approval and consent to participate}

The study about tissues and blood from patients was approved by the Ethics Committee of Kumamoto University Graduate School of Medicine (Kumamoto, Japan). Written informed consent for the use of tissues and blood in this study was obtained from all patients.

\section{Consent for publication}

Not applicable.

\section{Competing interests}

The authors declare that they have no competing interests.

\section{Publisher's Note}

Springer Nature remains neutral with regard to jurisdictional claims in published maps and institutional affiliations.

\section{Author details}

${ }^{1}$ Department of Breast and Endocrine Surgery, Graduate School of Medical Sciences, Kumamoto University, 1-1-1 Honjo, Chuo-ku, Kumamoto City 860-8556, Japan. ${ }^{2}$ Department of Molecular-Targeting Therapy for Breast Cancer, Kumamoto University Hospital, 1-1-1 Honjo, Chuo-ku, Kumamoto 860-8556, Japan. ${ }^{3}$ Department of Endocrinological and Breast Surgery, Graduate School of Medical Science, Kyoto Prefectural University of Medicine, 465 Kajii-cho, Hirokoji Agaru, Kawaramachi-dori, Kamigyo-ku, Kyoto 602-0841, Japan.
Received: 31 July 2016 Accepted: 13 November 2017

Published online: 22 November 2017

\section{References}

1. Karnik PS, Kulkarni S, Liu XP, Budd GT, Bukowski RM. Estrogen receptor mutations in tamoxifen-resistant breast cancer. Cancer Res. 1994;54(2):349-53.

2. Roodi N, Bailey LR, Kao WY, Verrier CS, Yee CJ, Dupont WD, Parl FF. Estrogen receptor gene analysis in estrogen receptor-positive and receptor-negative primary breast cancer. J Natl Cancer Inst. 1995;87(6):446-51.

3. Zhang QX, Borg A, Wolf DM, Oesterreich S, Fuqua SA. An estrogen receptor mutant with strong hormone-independent activity from a metastatic breast cancer. Cancer Res. 1997;57(7):1244-9.

4. Weis KE, Ekena K, Thomas JA, Lazennec G, Katzenellenbogen BS. Constitutively active human estrogen receptors containing amino acid substitutions for tyrosine 537 in the receptor protein. Mol Endocrinol. 1996; 10(11):1388-98

5. Robinson DR, Wu YM, Vats P, Su F, Lonigro RJ, Cao X, Kalyana-Sundaram S, Wang $R$, Ning $Y$, Hodges $L$, et al. Activating ESR1 mutations in hormoneresistant metastatic breast cancer. Nat Genet. 2013;45(12):1446-51.

6. Toy W, Shen Y, Won H, Green B, Sakr RA, Will M, Li Z, Gala K, Fanning S, King TA, et al. ESR1 ligand-binding domain mutations in hormone-resistant breast cancer. Nat Genet. 2013:45(12):1439-45.

7. Jeselsohn R, Yelensky R, Buchwalter G, Frampton G, Meric-Bernstam F, Gonzalez-Angulo AM, Ferrer-Lozano J, Perez-Fidalgo JA, Cristofanilli M, Gomez $\mathrm{H}$, et al. Emergence of constitutively active estrogen receptor-alpha mutations in pretreated advanced estrogen receptor-positive breast cancer. Clin Cancer Res. 2014;20(7):1757-67.

8. Merenbakh-Lamin K, Ben-Baruch N, Yeheskel A, Dvir A, Soussan-Gutman L, Jeselsohn R, Yelensky R, Brown M, Miller VA, Sarid D, et al. D538G mutation in estrogen receptor-alpha: a novel mechanism for acquired endocrine resistance in breast cancer. Cancer Res. 2013;73(23):6856-64.

9. Diaz LA Jr, Bardelli A. Liquid biopsies: genotyping circulating tumor DNA. J Clin Oncol. 2014;32(6):579-86.

10. Garcia-Murillas I, Schiavon G, Weigelt B, Ng C, Hrebien S, Cutts RJ, Cheang M, Osin P, Nerurkar A, Kozarewa I, et al. Mutation tracking in circulating tumor DNA predicts relapse in early breast cancer. Sci Transl Med. 2015 7(302):302ra133.

11. Schiavon G, Hrebien S, Garcia-Murillas I, Cutts RJ, Pearson A, Tarazona N Fenwick K, Kozarewa I, Lopez-Knowles E, Ribas R, et al. Analysis of ESR1 mutation in circulating tumor DNA demonstrates evolution during therapy for metastatic breast cancer. Sci Transl Med. 2015;7(313):313ra182.

12. Takeshita $T$, Yamamoto $Y$, Yamamoto-Ibusuki M, Inao T, Sueta A, Fujiwara $S$, Omoto $\mathrm{Y}$, Iwase $\mathrm{H}$. Clinical significance of monitoring ESR1 mutations in circulating cell-free DNA in estrogen receptor positive breast cancer patients. Oncotarget. 2016;7(22):32504-518.

13. Chandarlapaty S, Chen D, He W, Sung P, Samoila A, You D, Bhatt T, Patel P, Voi M, Gnant M, et al. Prevalence of ESR1 Mutations in Cell-Free DNA and Outcomes in Metastatic Breast Cancer: A Secondary Analysis of the BOLERO-2 Clinical Trial. JAMA Oncol. 2016;2(10):1310-15.

14. Pakdel F, Reese JC, Katzenellenbogen BS. Identification of charged residues in an $\mathrm{N}$-terminal portion of the hormone-binding domain of the human estrogen receptor important in transcriptional activity of the receptor. Mol Endocrinol. 1993;7(11):1408-17.

15. Li S, Shen D, Shao J, Crowder R, Liu W, Prat A, He X, Liu S, Hoog J, Lu C, et al. Endocrine-therapy-resistant ESR1 variants revealed by genomic characterization of breast-cancer-derived xenografts. Cell Rep. 2013:4(6): 1116-30.

16. De Mattos-Arruda L, Weigelt B, Cortes J, Won HH, Ng CK, Nuciforo P, Bidard FC, Aura C, Saura C, Peg V, et al. Capturing intra-tumor genetic heterogeneity by de novo mutation profiling of circulating cell-free tumor DNA: a proof-of-principle. Ann Oncol. 2014;25(9):1729-35.

17. Ma CX, Sanchez C, Gao F, Crowder R, Naughton M, Pluard T, Creekmore A, Guo Z, Hoog J, Lockhart AC, et al. A Phase I Study of the AKT Inhibitor MK2206 in Combination with Hormonal Therapy in Postmenopausal Women with Estrogen Receptor-Positive Metastatic Breast Cancer. Clin Cancer Res. 2016;22(11):2650-58

18. Spoerke JM, Gendreau S, Walter K, Qiu J, Wilson TR, Savage H, Aimi J, Derynck MK, Chen M, Chan IT, et al. Heterogeneity and clinical significance of ESR1 mutations in ER-positive metastatic breast cancer patients receiving fulvestrant. Nat Commun. 2016;7:11579. 
19. Fribbens C, O'Leary B, Kilburn L, Hrebien S, Garcia-Murillas I, Beaney M, Cristofanilli M, Andre F, Loi S, Loibl S, et al. Plasma ESR1 Mutations and the Treatment of Estrogen Receptor-Positive Advanced Breast Cancer. J Clin Oncol. 2016;34(25):2961-68.

20. Takeshita T, Yamamoto Y, Yamamoto-Ibusuki M, Inao T, Sueta A, Fujiwara S, Omoto Y, Iwase H. Droplet digital polymerase chain reaction assay for screening of ESR1 mutations in 325 breast cancer specimens. Transl Res. 2015;166(6):540-553 e542.

21. Gradishar WJ, Anderson BO, Blair SL, Burstein HJ, Cyr A, Elias AD, Farrar WB, Forero A, Giordano SH, Goldstein LJ, et al. Breast cancer version 3.2014. J Natl Compr Cancer Netw. 2014;12(4):542-90.

22. Takeshita T, Yamamoto Y, Yamamoto-lbusuki M, Tomiguchi M, Sueta A, Murakami K, Omoto Y, Iwase H. Comparison of ESR1 mutations in tumor tissue and matched plasma samples from metastatic breast cancer patients. Transl Oncol. 2017;10(5):766-71.

23. Takeshita T, Omoto Y, Yamamoto-lbusuki M, Yamamoto Y, Iwase H. Clinical significance of androgen receptor and its phosphorylated form in breast cancer. Endocr Relat Cancer. 2013;20(5):L15-21.

24. Toy W, Weir H, Razavi P, Lawson M, Goeppert AU, Mazzola AM, Smith A, Wilson J, Morrow C, Wong WL, et al. Activating ESR1 mutations differentially affect the efficacy of ER antagonists. Cancer Discov. 2017;7(3):277-87.

25. Chu D, Paoletti C, Gersch C, VanDenBerg DA, Zabransky DJ, Cochran RL, Wong HY, Toro PV, Cidado J, Croessmann S, et al. ESR1 Mutations in Circulating Plasma Tumor DNA from Metastatic Breast Cancer Patients. Clin Cancer Res. 2016;22(4):993-99.

26. Yanagawa T, Kagara N, Miyake T, Tanei T, Naoi Y, Shimoda M, Shimazu K, Kim SJ, Noguchi S. Detection of ESR1 mutations in plasma and tumors from metastatic breast cancer patients using next-generation sequencing. Breast Cancer Res Treat. 2017;163(2):231-40.

\section{Submit your next manuscript to BioMed Central and we will help you at every step:}

- We accept pre-submission inquiries

- Our selector tool helps you to find the most relevant journal

- We provide round the clock customer support

- Convenient online submission

- Thorough peer review

- Inclusion in PubMed and all major indexing services

- Maximum visibility for your research

Submit your manuscript at www.biomedcentral.com/submit

C) Biomed Central 